\title{
Article
}

\section{Transfer Behavior of Cesium Adsorbed on Clay Minerals in Aqueous Solution}

\author{
Yoshihiro OKAMOTO ${ }^{1, *}$, Takeshi OSUGI ${ }^{2}$, Hideaki SHIWAKU ${ }^{1}$ \\ and Mitsuo AKABORI ${ }^{3}$ \\ ${ }^{1}$ Quantum Beam Science Directorate, Japan Atomic Energy Agency (JAEA), 1-1-1 Kouto, Sayo-cho, Sayo-gun, \\ Hyogo 679-5148, Japan \\ ${ }^{2}$ Nuclear Science Research Institute, Japan Atomic Energy Agency (JAEA), \\ 2-4 Shirane, Shirakata, Tokai-mura, Naka-gun, Ibaraki 319-1195, Japan \\ ${ }^{3}$ Nuclear Science and Engineering Directorate, Japan Atomic Energy Agency (JAEA), \\ 2-4 Shirane, Shirakata. Tokai-mura, Naka-gun, Ibaraki 319-1195, Japan
}

\begin{abstract}
The transfer behavior of cesium adsorbed on some clay minerals in aqueous solution was investigated by X-ray absorption fine structure (XAFS) analysis of the Cs K-edge. The sample was prepared by mixing Cs-adsorbed mineral with a different pure clay mineral in water. The XAFS results of the dried mixture powder were compared with those obtained before mixing. It was recognized from the XAFS analysis for three kinds of clay minerals illite, kaolinite and vermiculite, that cesium was transferred from kaolinite to illite and vermiculite, and from illite to vermiculite. It can be concluded that cesium is transferred to and accumulated in vermiculite.
\end{abstract}

KEYWORDS: XAFS, cesium, transfer behavior, adsorption, X-ray, synchrotron radiation, clay mineral, migration, mixture

\section{Introduction}

Amid the extended decontamination conducted on radioactive cesium released during the accident at the Fukushima Daiichi Nuclear Power Plant, the understanding and elucidation of cesium behavior in the environment are important areas of investigation. From an early stage after the accident, efforts to elucidate the adsorption mechanism for each type of clay mineral have been made and tests on desorption have been carried out ${ }^{1-4)}$. Relevant to this, an understanding of the status of bound cesium and its changes during the decontamination process is required, and several projects have recently been initiated and are making progress. According to the large pool of knowledge accumulated to date, it has been determined that the desorption of cesium adsorbed by soil is not easy to achieve ${ }^{5)}$. If so, an important part of the question is the degree to which cesium is transferred among the mineral components in the soil, which is a mixture of various clay mineral components. One of the major natural phenomena that occurs when cesium is released into the environment is its adsorption by soil during an

* Corresponding author, E-mail: okamoto.yoshihiro@jaea.go.jp

DOI : 10.15669 /fukushimainsights.Vol.4.285

(C) 2021 Atomic Energy Society of Japan. All rights reserved.

Originally published in Transactions of the Atomic Energy Society of Japan (ISSN 1347-2879), Vol. 13, No. 3, p.113-118

(2014) in Japanese. (Japanese version accepted: June 16, 2014) 
extended period of repeated cycles of rainfall and drying. Puddles left on the ground following rainfall, and most of the cesium remaining in the shallow portion of the ground surface are then temporarily infiltrated in the water phase along with the clay minerals. The infiltration and drying are then repeated until the rainwater finally disappears. In this study, a test simulating an environment in which rainfall and its disappearance are repeated was conducted using synchrotron X-ray absorption fine structure (XAFS) analysis.

The main advantage of XAFS analysis is that it allows local environmental information regarding the specific element[s] in a multi-elemental composition system to be analyzed. Furthermore, it is an appropriate analysis method for determining the chemical status and coordination geometry of Cs adsorbed by clay minerals because it can precisely detect low concentrations of the targeted element. In this research, by taking advantage of the way that the chemical status of Cs in clay minerals is reflected in the XAFS spectrum, we tracked the variation of the chemical status in the minerals by soaking them in water.

\section{Experiments}

Three types of minerals were adopted for the test, namely, illite, vermiculite, and kaolinite (all of them purchased from Nichika, Inc., Japan). These minerals were soaked in a $0.02 \mathrm{M}$ $\mathrm{CsOH}$ solution for 1 week to allow Cs adsorption to occur. Next, the non-adsorbed Cs was removed through a cleaning process and dried. The results of a fluorescent X-ray analysis showed that the amount of $\mathrm{Cs}$ in the specimen (adsorbed amount) was approximately $0.4 \mathrm{wt} \%$ based on the equivalent oxide concentration. Furthermore, the amount of adsorption was similarly checked through the XAFS measurement of K absorption edge of Cs.

In spite of the possibility of influencing the skeleton of clay minerals by soaking them in an alkaline solution, there was no variation regarding the acquired EXAFS function, i.e., in the coordination geometry around Cs in spite of the different adsorption amounts of Cs between the tests with different soaking times of 3 h, 1 day, 1 week, and 2 weeks. Furthermore, it is considered that the influence was negligible because an almost identical EXAFS function was acquired through the tests when soaking in $0.02 \mathrm{M} \mathrm{CsCl}$ and $0.02 \mathrm{M} \mathrm{Cs}_{2} \mathrm{CO}_{3}$ including various clay minerals. After confirming the above, three prepared sets were adopted as the specimens for the Cs adsorption side. Next, two groups of large and small sized specimens were classified with a boundary of $75 \mu \mathrm{m}$ for three types of the same clay minerals in which Cs is not adsorbed. Three non-Cs adsorbing specimens no larger than $75 \mu \mathrm{m}$ were adopted. A total of $0.5 \mathrm{~g}$ of each specimen was mixed for the Cs adsorption and non-adsorption groups, placed in $10 \mathrm{~mL}$ of pure water, shaken, and left to stand at $25^{\circ} \mathrm{C}$. After the mineral components were deposited, the supernatant was removed and dried for measurement. The specimens used for testing are listed in Table 1. Three types of minerals with Cs adsorption (illite-Cs, vermiculite-Cs, and kaolinite-Cs), and six types of specimens after mixing (mix-1a through mix-6a) were subjected to measurement. To confirm repeatability, supplemental tests (mix-1b through mix-6b) were conducted using the same preparation and XAFS measurement methods. Furthermore, the cleaning agent was also measured (liq-1b through liq- $6 \mathrm{~b}$ ) because the possibility of migration of $\mathrm{Cs}$ to the cleaning agent side of the supernatant solution removed after mixing during the aqueous phase could not be ignored.

Synchrotron XAFS measurement was conducted using the BL11XU beamline of SPring- 8 . In this beamline, a monochromatic X-ray as high as $70 \mathrm{keV}$ is available using a liquid-nitrogen cooled $\mathrm{Si}(311)$ spectrometer ${ }^{6,7)}$. Using a monochromatic X-ray stabilized through a 
Table 1 Samples used in the XAFS measurement

\begin{tabular}{|c|c|c|c|c|}
\hline & $\begin{array}{l}\text { Cs-adsorbed } \\
\text { clay mineral }\end{array}$ & Pure clay mineral & Mixture & $\begin{array}{l}\text { Rinse } \\
\text { water }\end{array}$ \\
\hline \multirow{2}{*}{$\frac{1}{2}$} & \multirow{2}{*}{ Illite-Cs } & Pure Kaolinite & Mix-1a, mix $-1 b$ & Liq-1b \\
\hline & & Pure Vermiculite & Mix-2a, mix-2b & Liq $-2 b$ \\
\hline \multirow{2}{*}{$\frac{3}{4}$} & \multirow{2}{*}{ Vermiculite-Cs } & Pure Illite & Mix-3a, mix $-3 b$ & Liq-3b \\
\hline & & Pure Kaolinite & Mix $-4 a, \operatorname{mix}-4 b$ & Liq $-4 b$ \\
\hline \multirow{2}{*}{$\frac{5}{6}$} & & Pure Illite & Mix $-5 a$, mix $-5 b$ & Liq $-5 b$ \\
\hline & domte- & Pure Vermiculite & $\operatorname{Mix}-6 a, \operatorname{mix}-6 b$ & Liq-6b \\
\hline
\end{tabular}

monochromator stabilizer (MOSTAB) that stabilizes the dispersive crystal according to fluctuation in the incident X-rays, measurement was conducted within the range of $35.65-37.30 \mathrm{keV}$ on the targeted $\mathrm{K}$ absorption edge $\left(\mathrm{E}_{0}=35.985 \mathrm{keV}\right)$ of the Cs. For the XAFS measurement, a quick-scan XAFS (QAFS) measurement sweeping this energy range at high speed was conducted. The time required for an energy scan, i.e., the time needed to acquire the XAFS spectrum, was approximately $5 \mathrm{~min}$. The acquired data were compared after the background removal and normalization using WinXAS version 3.2 ${ }^{8}$. Furthermore, an EXAFS function $\mathrm{k}_{x}^{3}(\mathrm{k})$ was derived and the radial structural function $\left|\mathrm{FT}\left(\mathrm{k}_{x}^{3}(\mathrm{k})\right)\right|$ was acquired using a Fourier transformation.

\section{Results and Discussions}

\section{Cs in Three Types of Minerals}

The EXAFS function $\mathrm{k}_{x}^{3}(\mathrm{k})$ and the radial structural function of $\mathrm{Cs}$ adsorbed by illite, vermiculite, and kaolinite are shown in Figure 1. Illite and kaolinite showed quite similar functions, whereas vermiculite showed an EXAFS function with large amplitude and a radial structural function having a large second peak.

Illite has a fundamental 2:1-type layer structure consisting of two tetrahedral layers and an octahedral layer in between. Whereas vermiculite has the same 2:1-type structure, kaolinite has a 1:1-type form. The first peak of the radial structural function has a nearest-neighbor Cs-O correlation. Although the second peak is believed to have a Cs-Si correlation, a considerably large difference was observed between illite/kaolinite and vermiculite. The difference in the peak size of the radial structural function is largely attributable to the size of the coordination number and Debye-Waller factor, although the large difference in the second peak appears to be too big to be attributable to only one of them. Furthermore, vermiculite also shows higher peaks in a farther area than the others, which indicates a larger coordination number and the preservation of a good structural order over a long distance of the coordination environment of Cs captured in vermiculite. These differences [support][show a match with] the deduction that, while the Cs captured by illite and kaolinite is adsorbed mainly around the ends of the clay mineral layers, in vermiculite it is captured inside of the layer by swelling.

A characteristic difference is also observed between the Cs adsorbed by illite and kaolinite, which showed similar XAFS spectra. The EXAFS functions look almost identical, although the curve of illite shows a shoulder near $\mathrm{k}=4 \AA^{-1}$. This small difference was commonly recognizable in all XAFS spectra of the other Cs adsorbed by illite and kaolinite. Furthermore, while the 


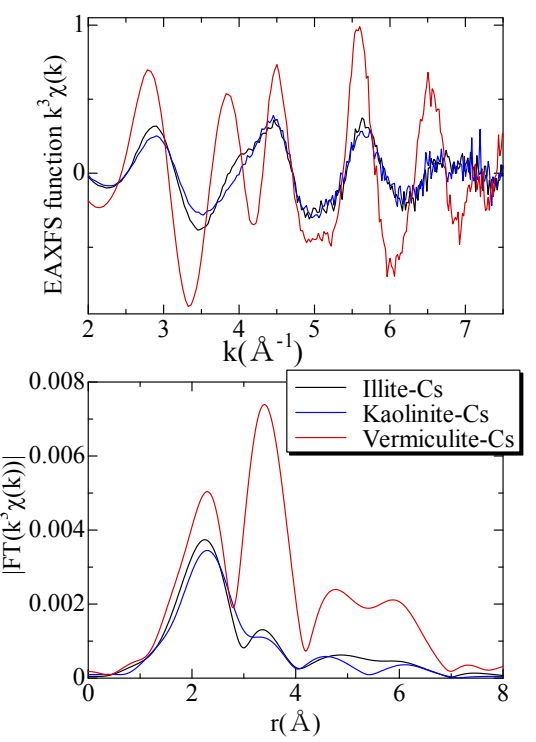

Figure 1 EXAFS functions $\mathrm{k}_{x}^{3}(\mathrm{k})$ and radial structural functions $\left|\mathrm{FT}\left(\mathrm{k}_{x}^{3}(\mathrm{k})\right)\right|$ of Cs-adsorbed illite, vermiculite and kaolinite

second peak of Cs adsorbed by illite shows a comparatively clear separation from the first peak in the radial structural function, kaolinite shows some ambiguity. The third and fourth peaks also show a difference. The existence of correlations such as Cs-Cs are presumed at around this distance, but are too obscure to be adopted for the purposes of comparison in this research owing to the fact that the effect of multiple scattering and other factors cannot be ignored.

The features of the clay minerals above were commonly observed in the Cs solution during the test at various soaking times. The attributions of the third peak and after the radial structural function are unclear, although it is thought that the determination of the difference in the coordination geometry around Cs captured in the three minerals through the XAFS analysis is possible with reasonable probability.

\section{Migration from Illite in Aqueous Phase}

The XAFS spectra of specimens prepared with a combination of illite on the Cs adsorption side and vermiculite and kaolinite on the non-adsorption side are shown in Figure 2. If the Cs adsorbed by illite does not move from the current position, no changes in spectra are expected. However, if Cs adsorbed by illite is desorbed and remains in an aqueous phase, the XAFS of Cs itself will not be observed through this measurement, or it will become difficult to observe owing to a small jump at the absorption edge proportional to the amount of Cs present. The results were clearly classified in two types of spectra. No changes were observed in the mixture with kaolinite from the spectrum of illite in which Cs is adsorbed. However, the mixture with vermiculite appears to show a match with the spectrum of Cs adsorbed by vermiculite. These results indicate that $\mathrm{Cs}$ adsorbed by illite migrated toward vermiculite whereas no migration toward kaolinite occurred.

The EXAFS and radial structural functions derived from various spectra are shown in Figure 3. Supporting the results derived through the comparison in Figure 2, the acquired results can be classified into two types of functions. 


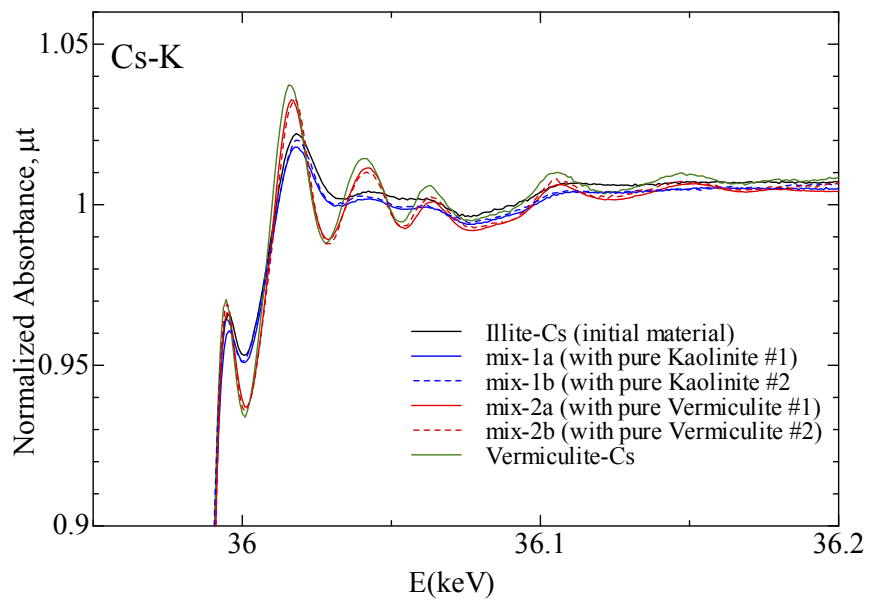

Figure 2 Normalized XAFS spectra of mixtures of Cs-adsorbed illite with pure kaolinite and pure vermiculite
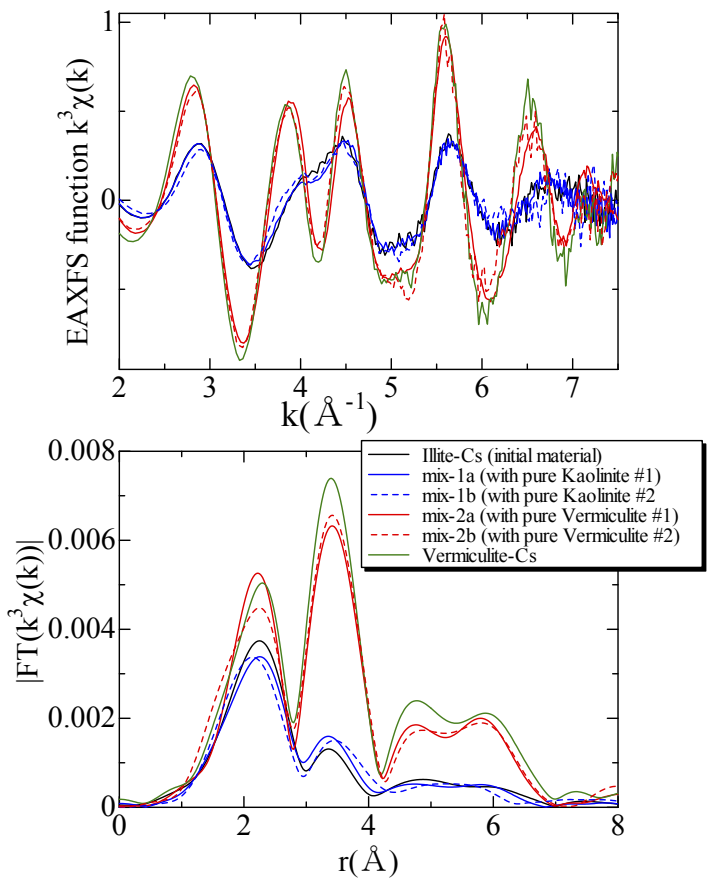

Figure 3 EXAFS functions $\mathrm{k}^{3}{ }_{x}(\mathrm{k})$ and radial structural functions $\left|\mathrm{FT}\left(\mathrm{k}^{3}{ }_{x}(\mathrm{k})\right)\right|$ of mixtures of Cs-adsorbed illite with pure kaolinite and pure vermiculite

The illite adsorbing Cs shows no change in the shoulder, which indicates that the characteristics of illite near $\mathrm{k}=4 \AA^{-1}$ of the EXAFS function and the second peak of the radial structural function remain clear. Consequently, it can be concluded that the Cs captured in the illite did not migrate toward the kaolinite. 


\section{Migration from Vermiculite in Aqueous Phase}

The XAFS spectra of the combination of vermiculite on the Cs adsorption side, and illite and kaolinite on the non-adsorption side, are shown in Figure 4. As can be clearly seen in the chart, all XAFS spectra show an identical feature, i.e., no change from the spectrum of Cs adsorbed in the vermiculite. This indicates that the Cs captured in vermiculite does not migrate even if mixed with illite and kaolinite in an aqueous phase.

Figure 5 shows the EXAFS and radial structural functions derived from each spectrum. All functions show a good match as if acquired from the same specimen. This indicates that both the EXAFS and radial structural functions have identical coordination geometries. Accordingly, this leads to the conclusion that the Cs adsorbed by vermiculite does not migrate even if mixed with illite or kaolinite in an aqueous phase, and remains in the vermiculite.

\section{Migration from Kaolinite in Aqueous Phase}

The XAFS spectra of the combination of kaolinite on the Cs adsorption side, and illite and vermiculite on the non-adsorption side, are shown in Figure 6. The spectra of specimens mixed with illite do not show a recognizable change, but the spectra of Cs adsorbed on illite and kaolinite exhibit an indistinguishably strong resemblance. However, when mixed with vermiculite, the features of kaolinite apparently disappear and the spectrum takes the form of Cs adsorbed by vermiculite.

Similarly, as in the case of Cs-adsorbed illite, the migration of Cs appears in an aqueous phase from kaolinite to vermiculite.

The EXAFS function derived from various spectra and the radial structural function are shown in Figure 7. For the specimens mixed with illite, a shoulder appears at approximately $\mathrm{k}=4 \AA^{-1}$ of the EXAFS function, and the second peak in the radial structural function is slightly clearer, indicating the features of $\mathrm{Cs}$ adsorbed by illite. This comparison implies the migration of Cs in kaolinite toward the illite side in the aqueous phase. In contrast, the specimen mixed with vermiculite shows that $\mathrm{Cs}$ is adsorbed by vermiculite, as confirmed through the comparison of the XAFS spectra.

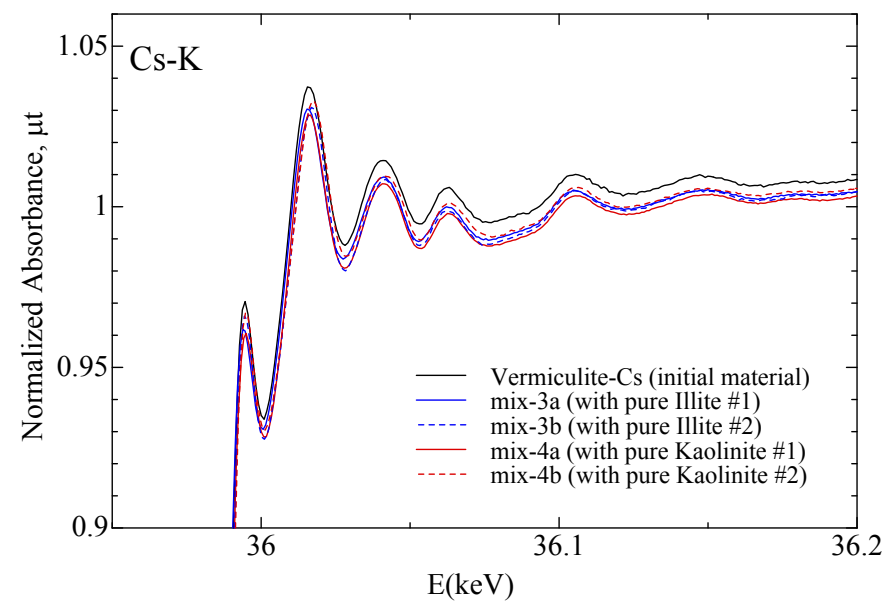

Figure 4 Normalized XAFS spectra of mixtures of Cs-adsorbed vermiculite with pure illite and pure kaolinite 

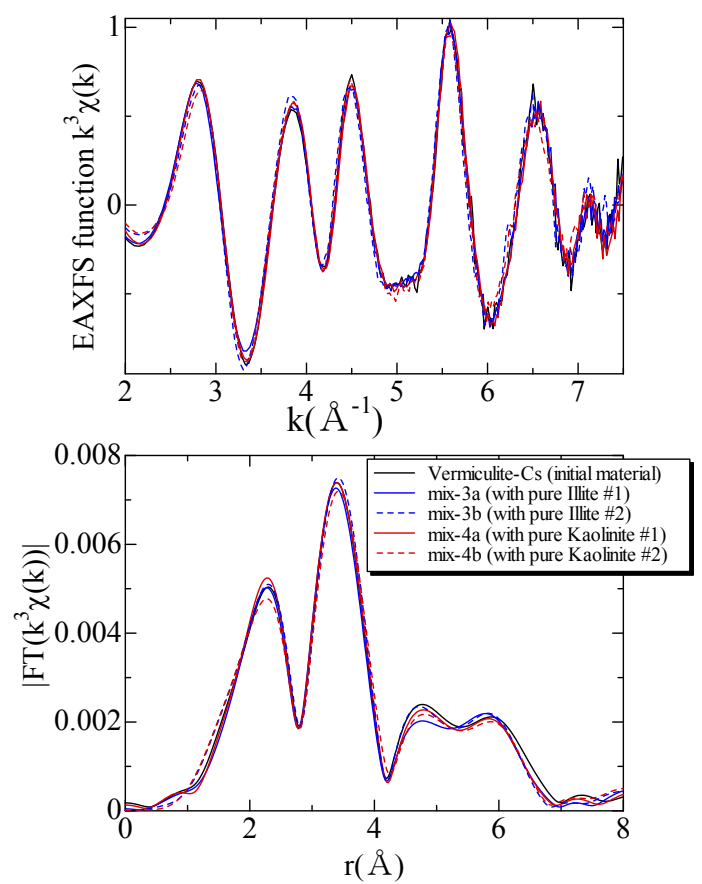

Figure 5 EXAFS functions $\mathrm{k}_{x}^{3}(\mathrm{k})$ and radial structural functions $\left|\mathrm{FT}\left(\mathrm{k}_{x}^{3}(\mathrm{k})\right)\right|$ of mixtures of Cs-adsorbed vermiculite with pure illite and pure kaolinite

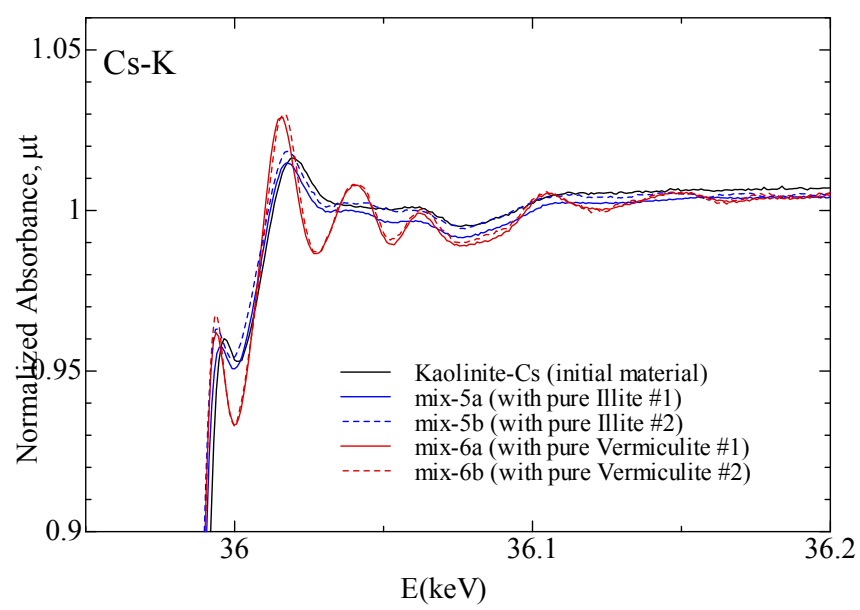

Figure 6 Normalized XAFS spectra of mixtures of Cs-adsorbed kaolinite with pure illite and pure vermiculite

The results above indicate that the Cs adsorbed by kaolinite migrates both toward illite and vermiculite in the aqueous phase.

\section{Analysis of Cleaning Agent}

The XAFS spectra of the cleaning agent sampled in the second experiment are shown in Figure 8. In two of the results, Cs-adsorbed illite (liq-1b) and Cs-adsorbed kaolinite (liq-5b) 

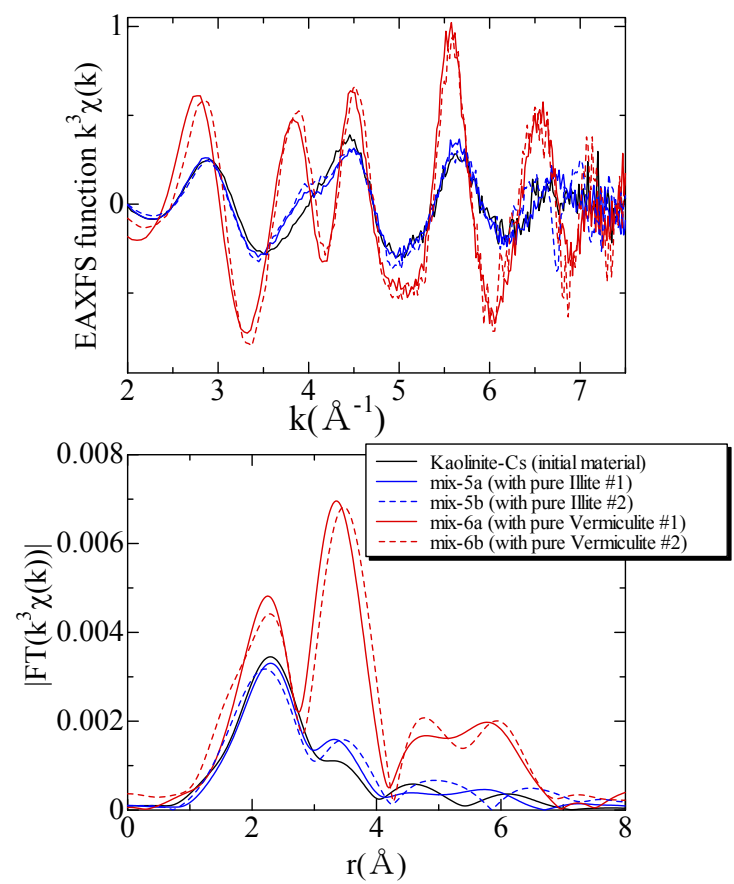

Figure 7 EXAFS functions $\mathrm{k}_{x}^{3}(\mathrm{k})$ and radial structural functions $\left|\mathrm{FT}\left(\mathrm{k}_{x}^{3}(\mathrm{k})\right)\right|$ of mixtures of Cs-adsorbed kaolinite with pure illite and pure vermiculite

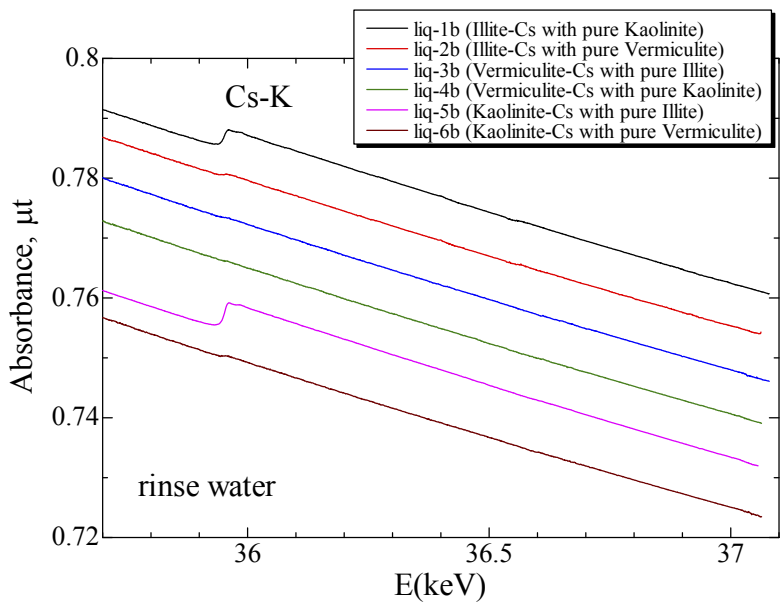

Figure 8 XAFS spectra of rinse water obtained in each mixture

clearly show the presence of Cs, which is confirmed through the presence of the absorption edge jump and the size, whereas such presence was not confirmed at all in the vermiculite. This matches the result showing that $\mathrm{Cs}$ does not migrate from vermiculite, i.e., it is possible to conclude that in the aqueous phase, Cs is not desorbed from vermiculite in such an amount that it can be confirmed using radio ray XAFS. The illite and kaolinite in which the presence of Cs is confirmed indicate the desorption of Cs in the aqueous phase. However, the level of the absorption edge jump is on the borderline for visual detection when the admixture is vermiculite. 
Table 2 Transfer behavior results of cesium adsorbed on clay minerals in aqueous solution

\begin{tabular}{lllll}
\hline $\begin{array}{c}\text { Cs-adsorbed } \\
\text { (initial metarial })\end{array}$ & $\begin{array}{c}\text { Pure clay } \\
\text { minerals }\end{array}$ & Transfer of Cs & $\begin{array}{c}\text { Rinse } \\
\text { water }\end{array}$ \\
\hline 1 & Illite & Kaolinite & No transfer & Detected \\
\hline 2 & Illite & Vermiculite & $\begin{array}{l}\text { Move to } \\
\text { Vermiculite }\end{array}$ & $\begin{array}{l}\text { Slightly } \\
\text { detected }\end{array}$ \\
\hline 3 & Vermiculite & Illite & No transfer & N.D. \\
\hline 4 & Vermiculite & Kaolinite & No transfer & N.D. \\
\hline 5 & Kaolinite & Illite & Move to Illite & Detected \\
\hline 6 & Kaolinite & Vermiculite & $\begin{array}{l}\text { Move to } \\
\text { Vermiculite }\end{array}$ & $\begin{array}{l}\text { Slightly } \\
\text { detected }\end{array}$ \\
\hline
\end{tabular}

These results indicate the re-adsorption of almost all desorbed Cs by vermiculite. They also indicate that a re-adsorption of Cs desorbed from illite into kaolinite, or Cs desorbed from kaolinite into illite, does not occur. However, as the results of an analysis on the main specimen side show, no migration from illite to kaolinite was seen, whereas there was migration from kaolinite to illite. Based on these results, it is easy to see that the amount of desorption of Cs from illite was small, whereas a large amount of Cs desorbed from kaolinite and migrated toward illite.

\section{Migration Phenomenon of Cs}

The integration of the above results and the considerations are shown in Table 2. There is a high possibility of migration of Cs released into the environment and adsorbed in the soil from kaolinite to illite and vermiculite, and from illite to vermiculite, during repeated rainfall and drying. The possibility that different results could be acquired is undeniable if the actual mineral composition in the soil is different because the tests conducted in this research were primitive, namely, the adoption of a mixture of two equal weights of minerals that adsorbed and did not adsorb Cs during an aqueous phase. There is another possibility of a different trend depending on the minerals or substances used.

The three clay minerals adopted for this research are contained in the soils of Fukushima Prefecture and its peripheral areas in considerably large quantities; it is quite significant that a clear migration of adsorbed Cs was confirmed between the materials during an aqueous phase. In particular, the migration toward vermiculite was clear, and the results of this research imply the possibility of a variation such as environmental condensation when Cs adsorbed in soil migrates toward vermiculite and accumulates during repeated rainfall.

\section{Conclusions}

The migration of Cs among three clay minerals contained in the soil of Fukushima Prefecture and its peripheral areas, namely, illite, kaolinite, and vermiculite, was investigated by mixing the adsorbed and non-adsorbed Cs during an aqueous phase using the synchrotron XAFS analysis method. As a result of the analysis, the migration of adsorbed Cs from kaolinite to illite or vermiculite, and from illite to vermiculite, was confirmed. It was also confirmed that there was no migration toward kaolinite, and almost no desorption of Cs took place from 
vermiculite. Among the three minerals, the migration toward vermiculite was noticeable, which indicates the possibility of the progress of migration and accumulation in vermiculite owing to the natural occurrence of repeated rainfall and drying.

The synchrotron radiation experiment conducted in this research applied research subjects 2012A3504 and 2012B3504 of SPring-8, a large synchrotron radiation facility.

\section{References}

1) S. Nakayama, "The Results of the decontamination pilot project and their application to the regional decontamination," Sangyo \& Kankyo, 41, 19-24 (2012). [in Japanese]

2) H. Sakurai, T. Kawamoto, K. Saito, M. Aritomi, H. Yamada et al., Kagaku, Kagaku-Dojin, 67, 16-46 (2012). [in Japanese]

3) H. Itoh, N. Seko, R. Kuroki, T. Yaita, H. Naganawa, S. Nakayama, "R\&D of removal technology of radioactive contaminants from the environment by using polymer absorbents," Housyasen-Kagaku, 93, 31-36 (2012). [in Japanese]

4) H. Naganawa, "Removal of radioactive cesium from contaminated soil by using poly-ion complex with clay,” J. Clay Sci. Soc. Jpn., 50, $52-57$ (2012). [in Japanese]

5) Department of Partnership Operations for Environmental Remediation, Headquarters of Fukushima Partnership Operations et al., "Investigation of radiocesium volatilization from soil by in-situ ground heating," JAEA-Res., 2011-026 (2011).

6) H. Shiwaku, T. Mitsui, K. Tozawa, K. Kiriyama, T. Harami, T. Mochizuki, AIP Conf. Proc., Eighth Int. Conf. on Synchrotron Radiation Instrumentation, 705, 659-662 (2004).

7) H. Shiwaku, T. Mitsui, K. Tozawa, "Introduction of liquid nitrogen cryogenic cooling system and development of multicrystal switching system on BL11XU at SPring-8," JAEA-Res., 2009-009 (2009). [in Japanese]

8) T. Ressler, "WinXAS: a program for X-ray absorption spectroscopy data analysis under MS-Windows," J. Synch. Rad., 5, 118-122 (1998). 